\title{
Influência do substrato dos telhados verdes na redução do escoamento superficial quando submetido às condições climáticas da Região Metropolitana do Recife
}

Influence of the substrate of green roofs in the reduction of surface runoff when subjected to the climatic conditions of the Metropolitan Region of Recife

Influencia del sustrato de techos verdes en la reducción de la escorrentía superficial cuando se somete a las condiciones climáticas de la Región Metropolitana de Recife

Recebido: 23/04/2021 | Revisado: 03/05/2021 | Aceito: 04/05/2021 | Publicado: 17/05/2021

Camila Barrêtto Rique de Barros

ORCID: https://orcid.org/0000-0002-7062-1502 Universidade de Pernambuco, Brasil E-mail: cbrb_pec@poli.br

Willames de Albuquerque Soares ORCID: https://orcid.org/0000-0003-3268-7241 Universidade de Pernambuco, Brasil E-mail: was@poli.br

Marco Aurelio Calixto Ribeiro de Holanda ORCID: https://orcid.org/0000-0002-0860-2458 Universidade Federal de Pernambuco, Brasil E-mail: macrh_pec@poli.br

\begin{abstract}
Resumo
O processo de urbanização acarreta a diminuição de áreas permeáveis, gerando uma redução na taxa de infiltração e consequente aumento do escoamento das águas pluviais, intensificando a frequência e a magnitude dos alagamentos. Contudo, o uso de telhados verdes vem se mostrando uma prática eficiente na redução e retardo desse escoamento. Nesse sentido, buscou-se identificar a classe textural ótima para o substrato de um telhado verde submetido às condições climáticas da Região Metropolitana do Recife (RMR). Para isso, realizou-se a calibração e validação do modelo Hydrus-1D com uso do volume drenado por um protótipo de telhado verde. Em seguida foram feitas simulações do fluxo de água no solo com diferentes classes texturais. Após a validação foi verificada uma boa eficiência do modelo na representação dos valores observados. Por fim, as classes texturais que apresentaram as maiores capacidades de retenção média foram a franca arenosa, franca, franco siltosa e silte. Com isso, para região estudada, o substrato do telhado verde deve ser composto por uma dessas categorias de solo. Na falta das mesmas, devem ser empregadas a areia, areia franca, franco argilo siltosa ou franco argilosa.
\end{abstract}

Palavras-chave: Hydrus-1D; Simulação; Capacidade de retenção.

\begin{abstract}
The urbanization process results in a reduction of permeable areas, generating a reduction in the infiltration rate and consequent increase in flow rainwater, intensifying the frequency and magnitude of flooding. However, the use of green roofs has been proving to be an efficient practice in reducing and delayed this flow. In this sense, we sought to identify the optimal textural class for the substrate of a green roof submitted to the climatic conditions of the Metropolitan Region of Recife (RMR). Then, the Hydrus-1D model was calibrated and validated using the volume drained by a green roof prototype. Then simulations of the soil water flow with different textural classes were made. After validation, a good efficiency of the model was verified in the representation of the observed values. Finally, the textural classes that presented the highest average retention capacities were sandy loam, loam, silt loam and silt. Therefore, for the studied region, the green roof substrate should be composed of one of these soil categories. In the absence of them, sand, loamy sand, silty clay loam or clay loam should be employed.
\end{abstract}

Keywords: Hydrus-1D; Simulation; Retention capacity.

\section{Resumen}

El proceso de urbanización se traduce en una reducción de las zonas permeables, generando una reducción en la tasa de infiltración y el consiguiente aumento del caudal de las aguas de lluvia, intensificando la frecuencia y magnitud de las inundaciones. Sin embargo, el uso de techos verdes ha sido una práctica eficiente en reducción y retraso de este flujo. En este sentido, buscamos identificar la clase textural óptima para el sustrato de un techo verde condiciones climáticas de la Región Metropolitana de Recife (RMR). Para ello, el modelo Hydrus-1D fue calibrado y validado con el uso de volumen drenado por un prototipo de techo verde. Luego se hicieron simulaciones del flujo de agua del 
suelo con diferentes clases texturales. Después de la validación, se verificó una buena eficiencia del modelo en la representación de los valores observados. Por último, las clases texturales que presentaron las mayores capacidades medias de retención fueron franco arenoso, franco, limo y franco limoso. Por lo tanto, para la región estudiada, el sustrato de techo verde debe estar compuesto por una de estas categorías de suelo. En ausencia de ellos, se debe emplear arena, areno franco, franco arcillo limoso o franco limoso.

Palabras clave: Hydrus-1D; Simulación; Capacidad de retención.

\section{Introdução}

A impermeabilização do solo, durante o processo de urbanização, acarreta a redução do coeficiente de infiltração e da taxa de evapotranspiração, gerando um aumento do escoamento superficial (De-Ville et al., 2018; Dutra e Silva, 2020). O aumento desse escoamento resulta na ocorrência dos alagamentos nos centros urbanos, que podem ser amenizados por meio da aplicação de técnicas compensatórias, como os telhados verdes (Wang et al., 2017; Wang et al., 2018; Mei et al., 2018).

A redução no escoamento das águas pluviais está relacionada com a capacidade de retenção dos telhados verdes, que ocorre por meio do processo de captação de água pelo solo e sua subsequente remoção pela evapotranspiração (Pettersson et al., 2019). Neste caso, as características hidrodinâmicas e a espessura do substrato estão diretamente ligadas a essa capacidade (Soulis et al., 2017; Shafique et al., 2018).

Contudo, a quantidade de água retida pelo substrato não depende apenas de sua profundidade e características hidrodinâmicas, mas também do clima que impulsiona a dinâmica da umidade do solo (Viola et al., 2017; Li et al., 2019). De acordo com Viola et al. (2017), o desempenho do telhado verde, quanto à retenção, aumenta quando a chuva e a evapotranspiração potencial possuem a mesma sazonalidade durante o ano hidrológico, como ocorre no clima subtropical úmido.

Diante disso, o uso de ferramentas capazes de realizar simulações são importantes na predição do comportamento dessa técnica compensatória (Bouzouidja et al., 2018). A exemplo disso, tem-se os modelos de transporte de água em meios porosos, que são relevantes na análise da capacidade de retenção dos telhados verdes e consequente diminuição do escoamento superficial (Soulis et al., 2017; Li et al., 2019).

Conforme afirma Costa et al. (2020), os modelos com base na solução numérica da equação de Richards, como Hydrus-1D, têm sido os mais utilizados para estimativa dos processos de transferência de água no solo. Esse modelo apresentou um bom desempenho ao ser utilizado em estudos que buscavam analisar o comportamento dos telhados verdes, como técnica compensatória de drenagem urbana (Santos et al., 2013; Bouzouidja et al., 2018).

Contudo, existe uma lacuna a respeito do uso dessa técnica, sendo necessária a realização de pesquisas locais, considerando que cada país tem diferentes condições climáticas e forma de urbanização (Pettersson et al., 2019). No Brasil, a compreensão da aplicabilidade regional é essencial considerando as diferenças climáticas observadas ao longo de sua vasta extensão territorial (Castro et al., 2020).

Com isso, este estudo buscou avaliar a redução do escoamento superficial, mediante aplicação de telhados verdes compostos por substratos de diferentes classes texturais, por meio de simulações no Hydrus-1D. Bem como, procurou-se identificar a classe textural com melhor desempenho na retenção dos volumes precipitados, sob as condições climáticas da RMR.

\section{Metodologia}

Para o estudo, foram usados os volumes drenados por um protótipo de telhado verde instalado e monitorado na RMR para calibração e validação do modelo Hydrus-1D. Em seguida, foram realizadas simulações com substratos de diferentes classes texturais, buscando avaliar a capacidade de retenção dos mesmos. 


\subsection{Hydrus-1D}

Foi reproduzido o perfil do protótipo de telhado verde no Hydrus-1D, com substrato composto por dois materiais (Solo 1 e Solo 2) e profundidade de $110 \mathrm{~mm}$. Com relação às condições climáticas, as variáveis atmosféricas de entrada do modelo foram obtidas com uso de uma estação meteorológica Oregon Scientific WMR300 instalada ao lado do protótipo. Para a descrição do comportamento hidráulico do solo não saturado, utilizou-se o modelo de Van Genuchten (1980), não sendo considerada a histerese.

A evapotranspiração potencial foi estimada pelo método de Hargreaves (1994), que possibilita a estimativa desse parâmetro de forma mais simples. De acordo com Freitas et al. (2018), esse modelo apresentou um bom resultado, ao avaliarem o cálculo da evapotranspiração diária por diferentes modelos em Pernambuco. Para o cálculo foram utilizados a Latitude, as temperaturas máxima e mínima diárias e o dia para o qual esses dados foram fornecidos. Além disso, os parâmetros relacionados ao crescimento da vegetação (grama esmeralda) e o índice de área foliar (LAI), que foi calculado por meio da fórmula disponível no Hydrus-1D (Equação 1), foram necessários para a estimativa da evapotranspiração real.

\section{$\mathrm{LAI}=0,24$.Altura da grama}

Como condições de contorno superior, inferior e inicial, foram adotadas as atmosféricas com escoamento superficial, drenagem livre e a umidade inicial do substrato, respectivamente. A variável de entrada foi a precipitação diária. A representação esquemática do telhado verde, utilizado nas simulações realizadas com o Hydrus-1D, está presente na Figura 1.

Figura 1. Representação esquemática e condições de contorno adotas nas simulações.

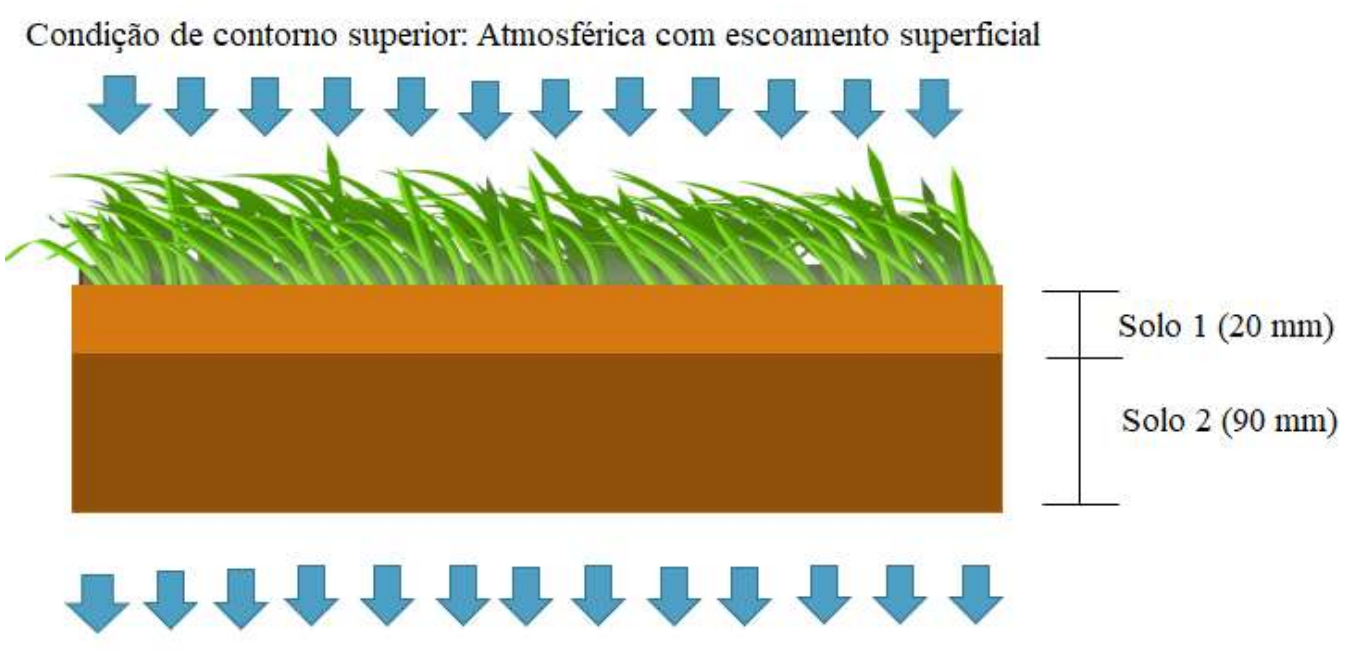

Condição de contorno inferior: Drenagem livre

Fonte: Autores.

Para a estimativa da captação de água pelas raízes, foi adotado o modelo de Feddes et al. (1978) com uso dos parâmetros sugeridos pelo Hydrus-1D para grama. São eles: a) o potencial matricial em que a raiz inicia a extração de água no solo (P0), b) a capacidade máxima de extração (P0pt), c) potencial limite de absorção, abaixo do qual as raízes não conseguem extrair água a uma taxa máxima, assumindo uma transpiração potencial de $0,5 \mathrm{cmdia}^{-1}(\mathrm{P} 2 \mathrm{H})$ e $0,1 \mathrm{cmdia}^{-1}(\mathrm{P} 2 \mathrm{~L})$, d) por fim o potencial em que a extração de água cessa (P3). Além disso, foi considerada uma profundidade de $110 \mathrm{~mm}$ para as raízes. 


\subsubsection{Parâmetros hidrodinâmicos do solo}

Os parâmetros hidrodinâmicos do solo foram determinados por meio de funções de pedotransferência. A condutividade hidráulica saturada do solo (Ks) foi estimada mediante equação de Cosby et al. (1984) (CPFT) com uso dos teores de areia e argila do solo. Além de necessitar de poucos dados de entrada, essa função mostrou bons resultados quando utilizada em estudos locais (Holanda e Soares, 2019; Macêdo e Soares, 2020).

Para os solos arenosos e francos utilizou-se as funções propostas por Barros et al. (2013) (BPFT) para estimativa dos valores da umidade volumétrica residual e saturada $(\theta \mathrm{r}$ e $\theta$ s) e dos parâmetros $\alpha$ e n, com uso dos teores de areia e argila do solo. Devido à ausência de amostras de solos argilosos no desenvolvimento das BPFT, foram utilizadas as funções de pedotransferência desenvolvidas por Medrado e Lima (2014) (MPFT) para os solos argilo arenoso, argilo siltoso e argiloso.

Os valores da densidade aparente do solo (Ds), densidade das partículas (Dp) e os teores de matéria orgânica (MO) das classes texturais argila, argilo arenosa e argilo siltosa, foram as médias dos valores disponíveis no Hydrophysical Database for Brazilian Soils (HYBRAS). Esses valores foram utilizados como dados de entrada da MPFT e estão apresentados na Tabela 1.

Tabela 1. Dados de entrada para MPFT.

\begin{tabular}{lccc}
\hline Propriedades físicas & \multicolumn{3}{c}{ Classes Texturais } \\
\cline { 2 - 4 } & Argila & Argilo arenosa & Argilo siltosa \\
\hline Ds $\left(\mathrm{gcm}^{-3}\right)$ & 1,240 & 1,420 & 1,170 \\
$\mathrm{MO}(\%)$ & 2,610 & 1,740 & 4,110 \\
$\mathrm{Dp}\left(\mathrm{gcm}^{-3}\right)$ & 2,659 & 2,573 & 2,594 \\
\hline
\end{tabular}

Fonte: Autores.

O uso das funções de pedotransferência foi optado devido à falta de representatividade de algumas classes texturais no banco de dados do HYBRAS, o que impossibilitou o uso das médias dos parâmetros hidrodinâmicos, para cada categoria de solo, disponíveis pelo mesmo.

\subsection{Calibração e validação do Hydrus-1D}

Para a calibração do Hydrus-1D, foram utilizados os volumes drenados pelo protótipo do telhado verde durante os primeiros 85 dias do período de monitoramento (11 de janeiro a 23 de junho de 2020).

Essa calibração foi feita de forma manual pelo método de tentativa e erro. Inicialmente, foram feitos ajustes nos parâmetros Feddes et al. (1978). Como valor inicial, utilizou-se os valores para grama sugeridos pelo modelo (Tabela 2), e realizou-se ajustes de $\pm 10, \pm 15$ e $\pm 20 \%$.

Em seguida, as alturas da vegetação foram ajustadas em $\pm 5, \pm 10, \pm 15, \pm 20, \pm 25 \%, \pm 30 \%$. Devido as dificuldades de acesso e o crescimento não uniforme, essas alturas foram estimadas por meio da função apresentada por Silva et al. (2011), na qual a altura da grama esmeralda (y(d)) em cm é dada em função dos dias de plantio (d), Equação 2. As alturas foram estimadas para o meio (42 dias) e o fim ( 85 dias) do período estudado.

$$
y(d)=0,0425 d-0,7588
$$


Tabela 2. Valores iniciais dos parâmetros de entrada usados na calibração.

\begin{tabular}{ccccccc}
\hline P0 (mm) & P0pt (mm) & P2H (mm) & P2L (mm) & P3 (mm) & Y42 (mm) & Y85 (mm) \\
\hline-100 & -250 & -3000 & -10000 & -80000 & 10,41 & 28,53 \\
\hline
\end{tabular}

Fonte: Autores.

O cálculo dos parâmetros hidrodinâmicos do solo foi feito com uso dos percentuais de areia e argila do Solo 1 (87,9\% de areia e 10,8\% de argila) e do Solo 2 (91,5\% de areia e 7,6\% de argila), os quais foram classificados como areia franca e areia, respectivamente. Esses teores foram definidos por meio do ensaio de granulometria segundo a NBR 7181 (ABNT, 2016).

Após a calibração, foi realizada a validação do modelo com uso dos dados atmosféricos observados durante o período de 05 de abril a 23 de junho de 2020.

\subsection{Análise estatística}

A análise da calibração e validação do Hydrus-1D foi feita por meio do comparativo gráfico entre os volumes drenados pelo protótipo de telhado verde (observados) e os simulados, buscando analisar a concordância entre esses valores.

Além disso, foi feita a análise estatística da calibração e validação, por meio dos seguintes índices estatísticos: coeficiente de correlação (r), coeficiente de determinação $\left(R^{2}\right)$, eficiência de Nash-Sutcliffe (NSE) (Equação 3) e raiz quadrada de erro médio (RMSE), Equações 4. Para qualificar o RMSE, foi utilizada a diretriz publicada por Singh et al. (2005) denominada razão de desvio padrão dos dados observados (RSR) mostrada na Equação 5.

$$
\begin{aligned}
& \mathrm{NSE}=1-\left(\frac{\Sigma(\mathrm{O} i-\mathrm{Si})^{2}}{\left.\sum(\mathrm{O} \mathbf{i}-\mathbf{O m})^{2}\right)}\right. \\
& \text { RMSE }=\sqrt{\frac{\sum(\mathbf{O i}-\mathrm{Si})^{2}}{\mathrm{~N}}} \\
& \text { RSR }=\frac{\text { RMSE }}{\sqrt{\frac{\sum(\mathrm{Oi}-\mathrm{Om})^{2}}{\mathrm{~N}}}}
\end{aligned}
$$

Onde: Oi são os dados observados, Om é a média dos dados observados, Si são os dados simulados e N é o número de observações. Para qualificação do NSE e do RSR foi utilizada a classificação da Tabela 3.

Tabela 3. Classificação do desempenho dos modelos hidrológicos com base no NSE e RSR.

\begin{tabular}{ccc}
\hline Avaliação de desempenho & NSE & RSR \\
\hline Muito bom & $0,75<\mathrm{NSE} \leq 1$ & $0,00 \leq \mathrm{RSR} \leq 0,50$ \\
Bom & $0,65<\mathrm{NSE} \leq 0,75$ & $0,50<\mathrm{RSR} \leq 0,60$ \\
Satisfatório & $0,50<\mathrm{NSE} \leq 0,65$ & $0,60<\mathrm{RSR} \leq 0,70$ \\
Insatisfatório & $\mathrm{NSE} \leq 0,50$ & $\mathrm{RSR}>0,70$ \\
\hline
\end{tabular}

Fonte: Moriasi et al. (2007). 
Essa classificação foi obtida por Moriasi et al. (2007) ao analisarem valores relatados na literatura durante a avaliação de modelos hidrológicos, Tabela 3. Essa classificação também foi adotada por Hakimdavar et al. (2014) e Soulis et al. (2017) na calibração e validação do Hydrus-1D.

\subsection{Simulação no Hydrus-1D}

Após a calibração e validação, com uso dos dados experimentais, foram realizadas simulações para o período referente a 05 de abril a 23 de junho de 2020. Para as simulações, foram escolhidas composições granulométricas representativas de cada uma das 12 classes texturais existentes para o Solo 2 e observada a capacidade de retenção do substrato. Os parâmetros hidrodinâmicos do Solo 1, por consistir no solo contido no tapete de grama, e os demais dados de entrada do Hydrus-1D foram mantidos os mesmos utilizados durante a validação.

A capacidade de retenção das águas pluviais consiste na taxa referente ao volume capitado pelo telhado verde e posteriormente evapotranspirado, segundo Pettersson et al. (2019). A mesma foi calculada com base nos volumes totais drenados pelo telhado verde e precipitado durante o período, de acordo com a Equação 6. Assim como utilizado por Hakimdavar et al. (2014) e Franco et al. (2019).

$$
\mathrm{RC}=\frac{\mathrm{P}-\mathrm{Rgr}}{\mathrm{P}} .100
$$

Onde: RC é a capacidade de retenção das águas pluviais (\%), P é o volume precipitado e Rgr é o volume drenado pelo telhado verde.

Além disso, foi realizada a análise do intervalo de confiança buscando identificar se existe diferença significativa entre a capacidade de retenção das diferentes classes texturais. Para isso, foram calculados a média, desvio padrão e o intervalo de confiança, com nível de significância de 5\%.

\section{Resultados e Discussão}

\subsection{Parâmetros hidrodinâmicos do solo na calibração e validação}

Os parâmetros hidrodinâmicos, estimados pela BPFT e CPFT para os Solos 1 e 2, utilizados na calibração e validação do modelo estão apresentados na Tabela 4.

Tabela 4. Parâmetros hidrodinâmicos dos Solos 1 e 2 usados como dados de entrada para a calibração e validação do modelo Hydrus-1D.

\begin{tabular}{cccccc}
\hline & $\begin{array}{c}\alpha \\
\left(\mathrm{mm}^{-1}\right)\end{array}$ & $\begin{array}{c}\theta \mathrm{r} \\
\left(\mathrm{mm}^{3} \mathrm{~mm}^{-3}\right)\end{array}$ & $\begin{array}{c}\theta \mathrm{s} \\
\left(\mathrm{mm}^{3} \mathrm{~mm}^{-3}\right)\end{array}$ & $\begin{array}{c}\mathrm{n} \\
(-)\end{array}$ & $\begin{array}{c}\mathrm{Ks} \\
\left(\mathrm{mm}_{\mathrm{dia}}{ }^{-1}\right)\end{array}$ \\
\hline Solo 1 & 0,005 & 0,037 & 0,392 & 1,774 & 1672 \\
Solo 2 & 0,006 & 0,020 & 0,417 & 1,798 & 1944 \\
\hline
\end{tabular}

Fonte: Autores.

Os valores estimados dos parâmetros hidrodinâmicos do solo estão de acordo com valores obtidos por outros pesquisadores como Santos et al. (2013), ao caracterizarem o substrato utilizado em um telhado verde no município de Caruaru-PE, para o solo franco arenoso.

Além disso, esses valores estão dentro do intervalo de variação observado por Macêdo e Soares (2020) ao determinarem as propriedades hidrodinâmicas em solos do Recife-PE, com uso de diferentes métodos. 


\subsection{Parâmetros hidrodinâmicos do solo utilizados nas simulações}

Os valores obtidos para os parâmetros hidrodinâmicos por meio da BPFT, MPFT e CPFT, utilizados como dados de entrada do modelo Hydrus-1D, em cada uma das simulações, estão apresentados na Tabela 5.

Tabela 5. Parâmetros hidrodinâmicos dos solos usados como substrato nas simulações do Hydrus-1D.

\begin{tabular}{lccccc}
\hline Classe Textural & $\begin{array}{c}\theta \mathrm{r} \\
\left(\mathrm{mm}^{3} \mathrm{~mm}^{-3}\right)\end{array}$ & $\begin{array}{c}\theta \mathrm{s} \\
\left(\mathrm{mm}^{3} \mathrm{~mm}^{-3}\right)\end{array}$ & $\begin{array}{c}\alpha \\
\left(\mathrm{mm}^{-1}\right)\end{array}$ & $\begin{array}{c}\mathrm{n} \\
(-)\end{array}$ & $\begin{array}{c}\mathrm{Ks} \\
\left(\mathrm{mm}_{\mathrm{dia}}{ }^{-1}\right)\end{array}$ \\
\hline Areia (A) & 0,013 & 0,338 & 0,007 & 1.804 & 1936 \\
Areia franca (AF) & 0,027 & 0,361 & 0,007 & 1.770 & 1449 \\
Franco arenosa (FA) & 0,067 & 0,390 & 0,006 & 1.702 & 871 \\
Franca (F) & 0,123 & 0,442 & 0,005 & 1.601 & 392 \\
Franco siltosa (FS) & 0,152 & 0,488 & 0,005 & 1.536 & 219 \\
Silte (S) & 0,139 & 0,535 & 0,007 & 1.526 & 164 \\
Franco argilo arenosa (FAA) & 0,154 & 0,390 & 0,003 & 1.591 & 485 \\
Franco argilo siltosa (FAS) & 0,220 & 0,494 & 0,003 & 1.444 & 131 \\
Franco argilosa (Far) & 0,184 & 0,436 & 0,003 & 1.525 & 272 \\
Argilo arenosa (AA) & 0,125 & 0,275 & 0,006 & 1.260 & 336 \\
Argilo siltosa (AS) & 0,239 & 0,485 & 0,007 & 1.207 & 85 \\
Argila (Ar) & 0,180 & 0,410 & 0,006 & 1.255 & 151 \\
\hline
\end{tabular}

Fonte: Autores.

Os valores do parâmetro $\theta \mathrm{r}$ variaram entre 0,013 e $0,239 \mathrm{~mm}^{3} \mathrm{~mm}^{-3}$, verificando-se os maiores valores para os solos com maior quantidade de componentes finos (silte e argila). O parâmetro $\theta$ s apresentou valores entre 0,338 e $0,535 \mathrm{~mm}^{3} \mathrm{~mm}^{-3}$, com valores menores para os solos arenosos.

$\mathrm{O}$ aumento do $\theta \mathrm{r}$ do solo mais grossos para os maios finos também foi observado nos valores obtidos por Holanda et al. (2020) ao realizarem a caracterização hidrodinâmica de oito solos no Estado de Pernambuco. Além disso, esses autores observaram $\theta \mathrm{s}$ de 0,345 para areia franca. Enquanto para Silva Junior et al. (2020) o $\theta \mathrm{s}$ foi de 0,509 $\mathrm{mm}^{3} \mathrm{~mm}^{-3}$ e 0,583 $\mathrm{mm}^{3} \mathrm{~mm}^{-3}$ para argila. De acordo com o intervalo do HYBRAS, o $\theta$ r ficou entre $0,032 \mathrm{~mm}^{3} \mathrm{~mm}^{-3}$ e $0,207 \mathrm{~mm}^{3} \mathrm{~mm}^{-3}$ para os solos franco arenoso e argiloso, respectivamente. Ainda de acordo com o HYBRAS, o $\theta$ s apresentou valores entre 0,396 $\mathrm{mm}^{3} \mathrm{~mm}^{-3} \mathrm{e} 0,557 \mathrm{~mm}^{3} \mathrm{~mm}^{-3}$ para areia e argila, respectivamente. Essas informações ratificam os valores obtidos neste artigo.

O parâmetro $\alpha$ ficou entre 0,003 e $0,007 \mathrm{~mm}^{-1}$, não se observando uma tendência de aumento ou diminuição desse parâmetro em função do tipo de classe textural. Para o solo franco argilo arenoso, o valor encontrado corrobora com Holanda et al. (2020) que obtiveram valores entre $0,002 \mathrm{~mm}^{-1}$ e $0,003 \mathrm{~mm}^{-1}$, já para os solos franco arenoso e areia franca eles observaram $\alpha$ igual a $0,005 \mathrm{~mm}^{-1}$. Para a argila, Silva Junior et al. (2020) observaram $\alpha$ de $0,007 \mathrm{~mm}^{-1} \mathrm{e} 0,008 \mathrm{~mm}^{-1}$, estando de acordo com os valores encontrados neste artigo. Para o HYBRAS, o $\alpha$ foi de $0,005 \mathrm{~mm}^{-1}$, em relação à areia, e $0,039 \mathrm{~mm}^{-1}$ para argila. Porém, apesar dos valores serem superiores no caso dos solos argilosos, o intervalo para os mesmos variou entre $0,1 \mathrm{~mm}^{-1}$ e $0,00014 \mathrm{~mm}^{-1}$.

Para o parâmetro n obteve-se valores entre 1,804 e 1,207, verificando-se que há uma diminuição desse parâmetro para os solos com maiores teores de finos, assim como observado por Holanda et al. (2020). No HYBRAS o n ficou entre 3,252 para areia e 1,386 para argila, corroborando com o observado neste artigo.

Com relação à condutividade hidráulica saturada, foi obtido $1936 \mathrm{~mm} \cdot \mathrm{dia}^{-1}$ para a areia e $85 \mathrm{~mm} \cdot \mathrm{dia}^{-1}$ para argila 
siltosa. Esses parâmetros estão de acordo com os obtidos por outros pesquisadores como Santos et al. (2013), no qual o Ks foi de $1671 \mathrm{~mm} \cdot \mathrm{dia}^{-1}$ e Sousa (2019) que obteve $1642 \mathrm{~mm} \cdot \mathrm{dia}^{-1}$ para o solo arenoso. Holanda et al. (2020) observaram uma condutividade hidráulica saturada de $626 \mathrm{~mm} \cdot \mathrm{dia}^{-1}$ e $638 \mathrm{~mm} \cdot \mathrm{dia}^{-1}$ para solos francos argilo arenosos. O intervalo para o solo arenoso observado no HYBRAS, foi de $36 \mathrm{~mm} \cdot \mathrm{dia}^{-1}$ a $7820 \mathrm{~mm} \cdot \mathrm{dia}^{-1}$, enquanto para o solo argiloso esse intervalo foi de 11,7 mm.dia ${ }^{-1}$ a $24940 \mathrm{~mm} \cdot \mathrm{dia}^{-1}$. Isso mostra uma grande variabilidade desse parâmetro dentro de cada classe textural.

\subsection{Calibração do Hydrus-1D}

Ao realizar a calibração do Hydrus-1D, com base no volume drenado pelo telhado verde, verificou-se que os ajustes nos parâmetros de Feddes et al. (1978) não apresentaram diferença significativa entre os valores dos índices estatísticos obtidos em cada ajuste e também não se verificou mudanças significativas entre os hidrogramas.

Quanto aos ajustes realizados na altura da vegetação, o melhor conjunto observado foi de $+25 \%$ para a altura estimada pela função de Silva et al. (2011) para os dias 42 e 85, resultando em 13,09 e 35,67 mm de altura, respectivamente.

No hidrograma (Figura 2), pode-se observar que o modelo foi capaz de reproduzir as tendências crescentes e decrescentes dos dados observados ao longo do período, as quais indicam semelhança entre esses dados. Como afirma Singh et al. (2005), essa concordância entre as frequências indica uma simulação adequada.

Figura 2. Hidrograma do volume drenado observado e simulado após calibração do modelo Hydrus-1D e precipitação medida no período.

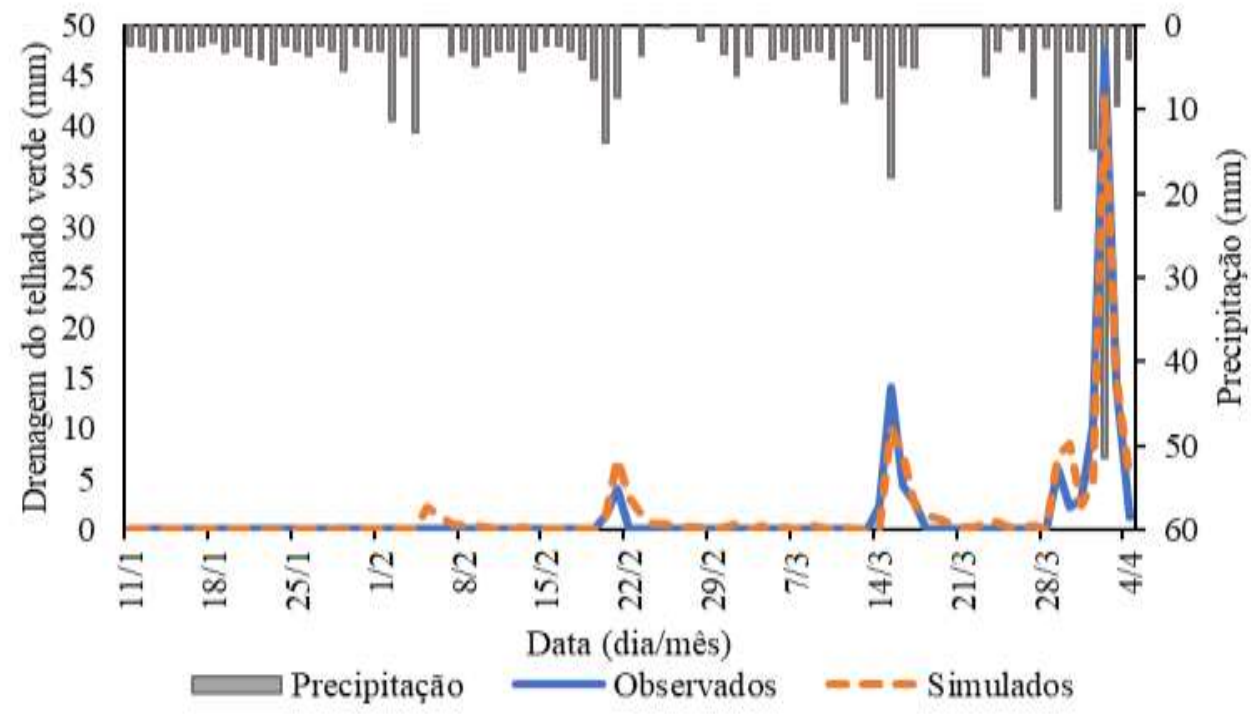

Fonte: Autores.

A partir do hidrograma, pôde-se verificar um aumento nos volumes precipitados durante o período observado, com a máxima de 51,56 mm no dia 2 de abril de 2020 no qual foi identificado o maior volume drenado pelo telhado verde (47,37 $\mathrm{mm}$ ). Na simulação, a primeira drenagem ocorreu no dia 05 de fevereiro de 2020, porém, no caso dos valores observados, o protótipo só apresentou a primeira drenagem para chuva de 13,97 mm, equivalente a 1,37 mm, no dia 20 de fevereiro de 2020.

Isso pode estar relacionado à subestimativa da evapotranspiração, devido ao uso de um modelo mais simples para cálculo da mesma. Essa ocorrência também foi observada por Barros et al. (2019) e Macêdo et al. (2017), ao estimarem esse parâmetro pelo método de Hargreaves em cidades litorâneas do Estado de Alagoas. Esses autores observaram que o modelo apresenta uma boa estimativa, porém subestimou a evapotranspiração potencial. 
Ademais, os resultados dos índices estatísticos utilizados na avaliação da eficiência do modelo (Tabela 6) indicam que o mesmo foi devidamente calibrado.

Tabela 6. Índices estatísticos da calibração.

\begin{tabular}{cccc}
\hline Índices estatísticos & Intervalo & Valores ótimos & $15 \%$ Altura \\
\hline $\mathrm{r}$ & $-1 \leq \mathrm{r} \leq 1$ & 1 & 0,970 \\
$\mathrm{R}^{2}$ & $0 \leq \mathrm{R}^{2} \leq 1$ & 1 & 0,941 \\
$\mathrm{NSE}$ & $\mathrm{NSE} \leq 1$ & 1 & 0,935 \\
$\mathrm{RMSE}$ & $0 \leq \mathrm{RMSE}$ & 0 & 1,436 \\
$\mathrm{RSR}$ & $0 \leq \mathrm{RSR}$ & 0 & 0,254 \\
\hline
\end{tabular}

Fonte: Autores.

Os coeficientes de correlação e determinação ficaram próximos ao valor ótimo. Já o RMSE, foi avaliado pelo RSR que ficou abaixo de 0,50 e o NSE ficou acima de 0,70, o que representa uma simulação muito boa, de acordo com Moriasi et al. (2007).

\subsection{Validação do Hydrus-1D}

$\mathrm{Na}$ validação, de acordo com o Hidrograma (Figura 3), a simulação com uso do Hydrus-1D apresenta uma boa reprodução dos eventos observados. Isso pode ser verificado pela tendência entre os valores simulados e observados.

Figura 3. Hidrograma do drenado observado e simulado na validação do Hydrus-1D e precipitação.

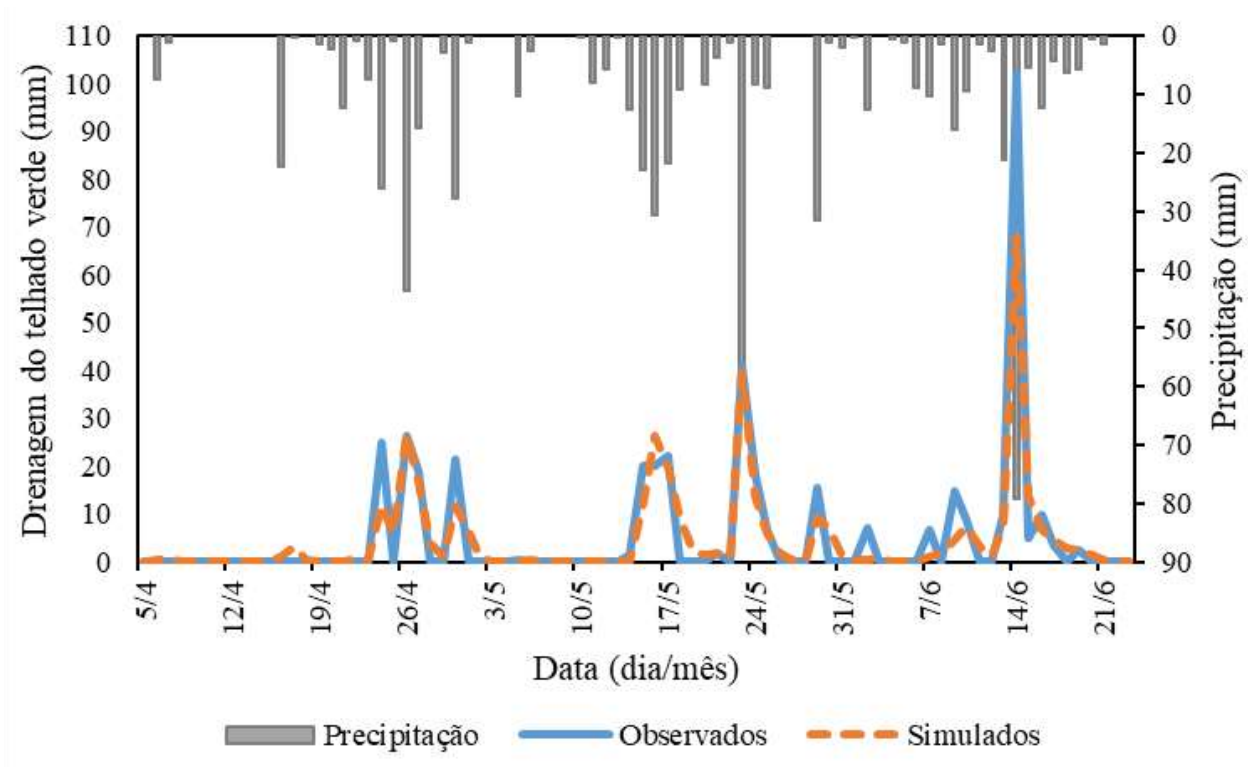

Fonte: Autores.

Com o aumento na intensidade das precipitações, quando comparadas ao período de calibração, pôde-se observar o aumento na ocorrência do volume drenado pelo telhado verde. Também se verificou que o Hydrus-1D subestimou esses volumes, o que pode estar relacionado à redução da evapotranspiração no período, devido à influência das barreiras de massas de ar que ocorrem durante as chuvas e reduzem a radiação solar. Essa influência não pode ser considerada durante a estimativa pelo modelo de Hargreaves (1994), visto que o modelo utiliza a radiação solar extraterrestre. Isso também foi observado por 
Freitas et al. (2018), que observaram uma grande variação na estimativa da evapotranspiração potencial com uso desse modelo durante o período com maiores precipitações.

A Tabela 7 apresenta os valores dos índices estatísticos obtidos na validação do modelo. Os resultados indicam que existe uma consistência entre os dados simulados e observados durante o experimento.

Tabela 7. Índices estatísticos obtidos na validação do modelo.

\begin{tabular}{cccc}
\hline Índices estatísticos & Intervalo & Valores ótimos & Validação \\
\hline $\mathrm{r}$ & $-1 \leq \mathrm{r} \leq 1$ & 1 & 0,948 \\
$\mathrm{R}^{2}$ & $0 \leq \mathrm{R}^{2} \leq 1$ & 1 & 0,899 \\
$\mathrm{NSE}$ & $\mathrm{NSE} \leq 1$ & 1 & 0,853 \\
$\mathrm{RMSE}$ & $0 \leq \mathrm{RMSE}$ & 0 & 5,043 \\
$\mathrm{RSR}$ & $0 \leq \mathrm{RSR}$ & 0 & 0,384 \\
\hline \multicolumn{5}{c}{ Fonte: Autores. }
\end{tabular}

Para validação, o modelo apresentou um desempenho muito bom, com base nos valores do NSE $=0,853$ e RSR $=$ 0,383. Além disso, valores de $\mathrm{R}^{2}$ próximos aos obtidos neste estudo foram observados por Santos et al. (2013), ao validarem o Hydrus-1D com base no volume drenado pelo telhado verde durante dois eventos de precipitação ( $21 \mathrm{~mm}$ e 39,5 mm), os quais apresentaram um coeficiente de determinação equivalente a 0,74 e 0,95 . O experimento foi realizado em Caruaru-PE.

\subsection{Simulações no Hydrus-1D}

A redução no escoamento superficial foi avaliada por meio da capacidade de retenção média do volume precipitado durante o período simulado, para cada uma das classes texturais. Além disso, foi observado o comportamento do telhado verde diante dos eventos diários buscando identificar a retenção máxima e mínima das classes texturais.

\subsubsection{Capacidade de retenção para todo o período de estudo}

Nas simulações, houveram mudanças nos volumes evapotranspirados e drenados pelo telhado verde à medida que se alterou a classe textural do substrato. A Tabela 8 apresenta esses volumes acumulados durante todo o período. 
Tabela 8. Volumes precipitado, evapotranspirado, drenagem do telhado verde e escoado superficialmente durante o período simulado para cada classe textural.

\begin{tabular}{lcccc}
\hline \multicolumn{1}{c}{ Classe Textural } & $\begin{array}{c}\text { Precipitação } \\
(\mathrm{mm})\end{array}$ & $\begin{array}{c}\text { EVT } \\
(\mathrm{mm})\end{array}$ & $\begin{array}{c}\text { Drenagem do } \\
\text { Telhado verde } \\
(\mathrm{mm})\end{array}$ & $\begin{array}{c}\text { Escoamento } \\
\text { superficial } \\
(\mathrm{mm})\end{array}$ \\
\hline Areia & 622,39 & 234,55 & 382,27 & - \\
Areia franca & 622,39 & 235,31 & 379,50 & - \\
Franco arenosa & 622,39 & 232,25 & 378,09 & - \\
Franco & 622,39 & 226,78 & 376,41 & - \\
Franco siltosa & 622,39 & 222,93 & 374,83 & - \\
Silte & 622,39 & 219,77 & 373,90 & - \\
Franco argilo arenosa & 622,39 & 214,53 & 389,14 & - \\
Franco argilo siltosa & 622,39 & 211,19 & 381,37 & - \\
Franco argilosa & 622,39 & 214,65 & 384,38 & - \\
Argilo arenosa & 622,39 & 208,90 & 395,89 & 0,23 \\
Argilo siltosa & 622,39 & 192,17 & 392,60 & 1,89 \\
Argilosa & 622,39 & 202,22 & 390,18 & - \\
\hline
\end{tabular}

Fonte: Autores.

A evapotranspiração foi menor que a drenagem do telhado verde em todas as classes texturais analisadas, indicando que os volumes retidos foram inferiores aos drenados. Isso porque, a capacidade de retenção do telhado verde consiste na parcela de água captada pelo solo por meio da infiltração e posteriormente evapotranspirada.

Provavelmente, o alto volume drenado se deve a alta frequência de chuvas observadas durante o período estudado. Como afirmam Hamouz et al. (2018), a performance dos telhados verdes na retenção e detenção são mais eficazes em eventos isolados de chuva do que em vários eventos com estreita proximidade temporal.

Essa frequência e o alto volume dos eventos de precipitação estão relacionados ao período em que o estudo foi realizado, que, é caracterizado pela redução nas temperaturas e aumento no volume de chuvas na RMR conforme Wanderley et al. (2018). Como a diminuição da temperatura influencia na redução da evapotranspiração, é necessário um intervalo mais extenso entre dois eventos chuvosos para o solo reestabelecer sua capacidade de armazenamento, como observado por alguns autores (Johannessen et al., 2018; Li et al., 2019; Cascone et al., 2019; Holanda e Soares, 2019).

A análise da capacidade de retenção média do período foi feita com base no intervalo de confiança, para um nível de significância de $5 \%$ (Figura 4). 
Figura 4. Intervalo de confiança da capacidade de retenção das classes texturais do solo.

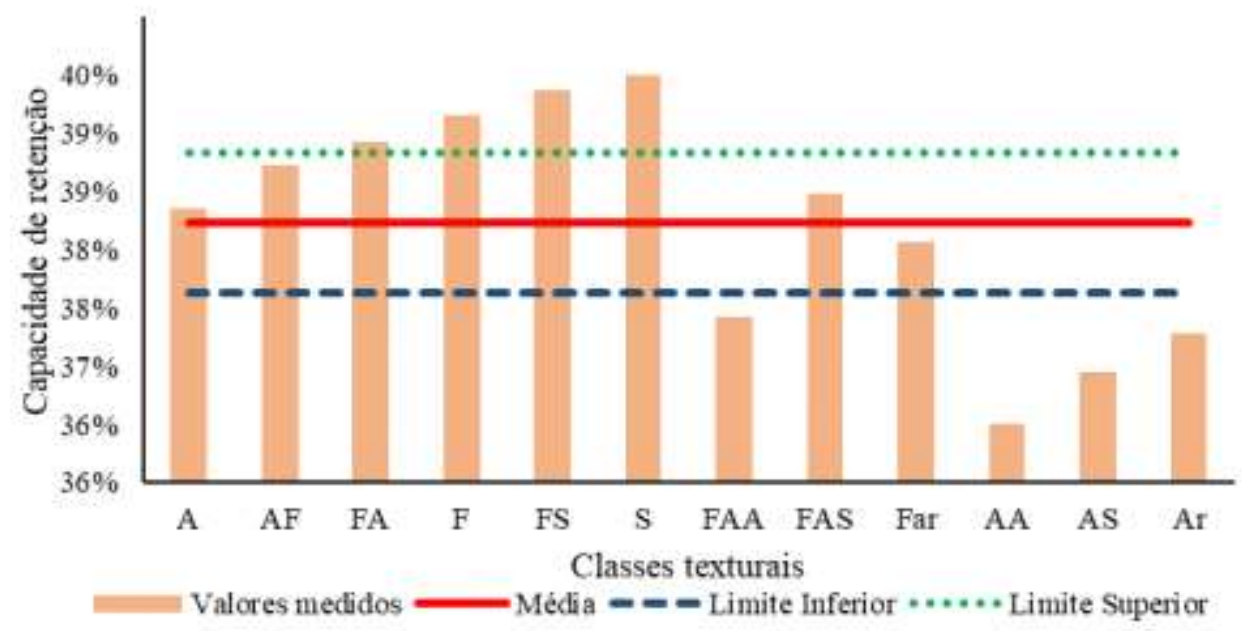

Fonte: Autores.

Quanto à capacidade de retenção média de todo o período, os telhados verdes com solos de textura franca arenosa, franca, franca siltosa e silte apresentaram os maiores valores. Já para as coberturas de areia, areia franca, franco argilo siltosa e franco argilosa, não se observou diferença significativa.

A capacidade de retenção média dos solos argilosos foram as mais baixas, com a menor capacidade de retenção observada para o solo argilo arenoso. A alta densidade do solo argiloso utilizado no estudo é indicação de uma alta compactação, o que reduz a porosidade e, consequentemente, a capacidade de retenção. A importância de uma baixa densidade e alta porosidade para os substratos de telhado verde são características observadas por Bouzouidja et al. (2018) ao avaliarem o comportamento hidrodinâmico de um telhado verde utilizando um substrato de baixa densidade aparente $\left(0,800 \mathrm{gcm}^{-3}\right)$ e alta porosidade (72\%), obtendo uma capacidade de retenção de $89 \%$.

Além disso, foi observado o escoamento superficial equivalente a $0,23 \mathrm{~mm}$ e $1,89 \mathrm{~mm}$ nos telhados verdes com substrato composto por solo argilo siltoso e argiloso. Isso pode ter ocorrido devido à baixa condutividade hidráulica, característica observada por Xie e Liu (2020). Ou seja, boas propriedades hidrodinâmicas são pré-requisitos para prevenir o escoamento superficial dos telhados verdes e a sobrecarga gerada pelo acumulo de água.

Diante disso, é importante observar o comportamento das classes texturais que não apresentaram escoamento superficial frente a precipitações mais intensas que ocorrem na RMR, com acumulados diários acima de $100 \mathrm{~mm}$. Esses volumes ocorrem com uma frequência elevada, como afirma Wanderley et al. (2018), que verificaram esses eventos extremos de precipitação em 41 dos 56 anos da série histórica de precipitação (1961-2016) da cidade do Recife-PE.

De forma geral, os telhados verdes simulados neste artigo, com substratos arenosos e francos, se mostraram eficientes na retenção dos volumes precipitados, tendo em vista o período com altas precipitações que segundo Moreira et al. (2017) se caracteriza como extremamente chuvoso para a RMR. As capacidades de retenção encontradas estão de acordo com o valor observado por Peixoto (2019), que observou uma retenção de 42,69\% após analisar o comportamento de telhados verdes extensivos durante seis eventos de precipitação com volumes de $10 \mathrm{~mm}$ a $66 \mathrm{~mm}$ na cidade do Recife-PE. Além disso, de acordo com Viola et al. (2017) os telhados verdes extensivos inseridos em regiões de clima tropical, como a área estudada, apresentam retenção média de 34\%, corroborando com os valores observados neste trabalho.

Quando comparada a capacidade de retenção verificada neste estudo com aquelas obtidas em estudos realizados em outras regiões, os resultados foram mais baixos que os encontrados por autores como Franco et al. (2019), que ao avaliarem a capacidade de retenção de telhados verdes extensivos em Santa Maria-RS observaram 75\% de retenção para o período de 
setembro de 2018 a março de 2019. Esses valores podem estar relacionados ao regime de chuva característico da região Sul do Brasil (subtropical) que, diferente da RMR, apresentam eventos de precipitação bem distribuídos ao longo do ano, o que aumenta a eficiência dos telhados verdes, como afirmam Viola et al. (2017) ao avaliarem a eficiência dos telhados verdes em diferentes regimes climáticos.

\subsubsection{Capacidade de retenção para eventos diários de precipitação}

Com o intuito de avaliar a capacidade de retenção dos telhados verdes, com diferentes classes texturais de substrato, em escala diária, foram analisados os volumes precipitados e drenados por cada um deles, sendo mostradas as que apresentaram a melhor (silte), intermediária (areia) e pior (argilo arenoso) eficiência.

O telhado verde com substrato siltoso gerou os volumes drenados, para cada evento de precipitação observado no período, apresentados na Figura 5.

Figura 5. Precipitação e drenagem do telhado verde utilizando substrato siltoso.

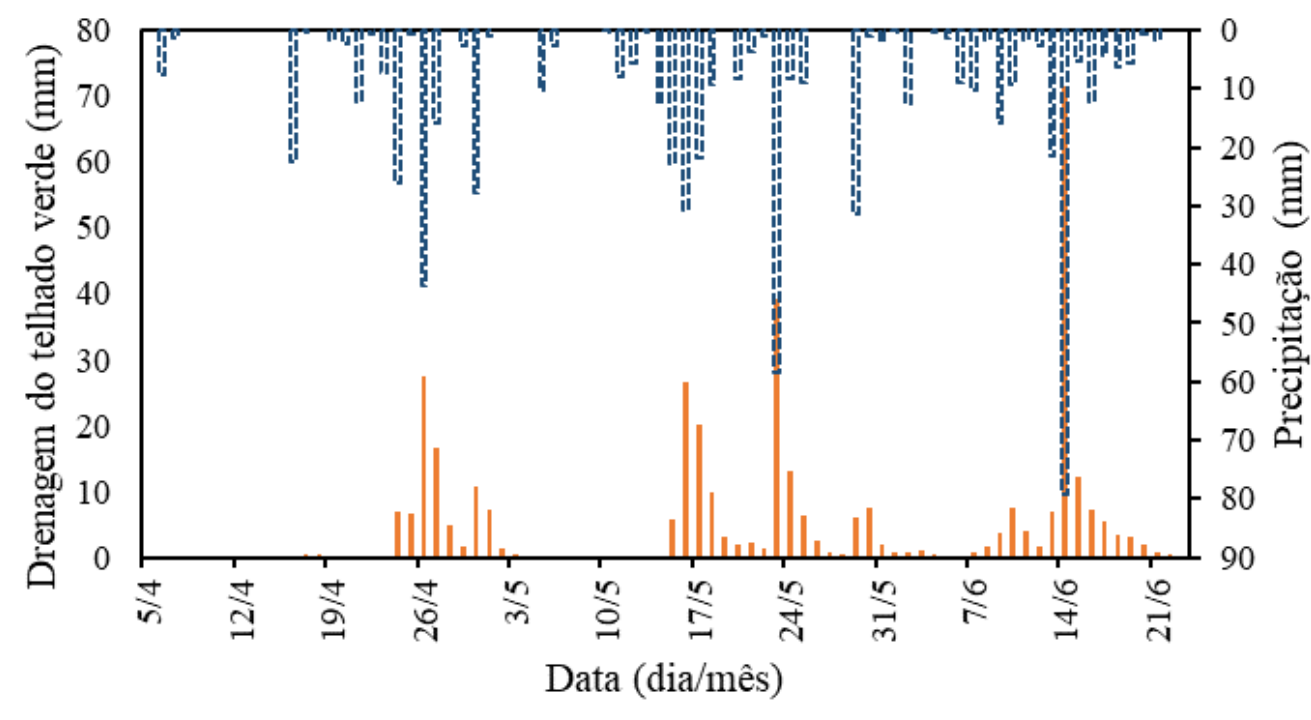

E Drenagem do telhado verde ¿ Precipitação

Fonte: Autores.

Durante o período simulado, foram observados dias $\operatorname{secos}(\mathrm{P}<2,2 \mathrm{~mm})$, com chuva muito fraca $(2,2 \mathrm{~mm} \leq \mathrm{P}<4,2$ $\mathrm{mm}$ ), chuva fraca $(4,2 \mathrm{~mm} \leq \mathrm{P}<8,4 \mathrm{~mm})$, moderada $(8,4 \mathrm{~mm} \leq \mathrm{P}<18,6 \mathrm{~mm})$, fortes $(18,6 \mathrm{~mm} \leq \mathrm{P}<55,3 \mathrm{~mm})$ e muito fortes ( $P \geq 55,3 \mathrm{~mm}$ ) seguindo a classificação de Souza et al. (2012) para as precipitações diárias na cidade de Recife-PE. De acordo com esses autores, após analisarem informações fornecidas pela Coordenadoria de Defesa Civil do Recife (CODECIR) relacionadas aos escorregamentos de barreiras, alagamentos e óbitos, verificaram que as chuvas moderadas e fortes já podem desencadear pontos de alagamento na RMR.

Para o telhado verde composto por silte, a capacidade de retenção diária ficou entre 4,93\% e 100\%. A menor delas, foi verificada no dia 31 de maio de 2020 para uma precipitação de 2,03 $\mathrm{mm}$. Essa baixa taxa pode estar relacionada a alta umidade do substrato, visto que, no dia 29 de maio de 2020, foi verificado uma retenção de 81,20\% para uma chuva de 31,49 mm e no dia 30 de maio de 2020 foi verificado uma drenagem do telhado verde superior ao volume precipitado. Ademais, esse telhado verde mostrou uma retenção $100 \%$ para uma precipitação de $22,35 \mathrm{~mm}$, o qual é referente ao dia 16 de abril de 2020, isso pode estar ligado ao intervalo seco antecedente (8-15 de abril de 2020). 
A Figura 6 apresenta os volumes diários precipitados durante o período simulado e o volume drenado pelo telhado verde com substrato arenoso.

Figura 6. Precipitação e drenagem do telhado verde utilizando substrato areia.

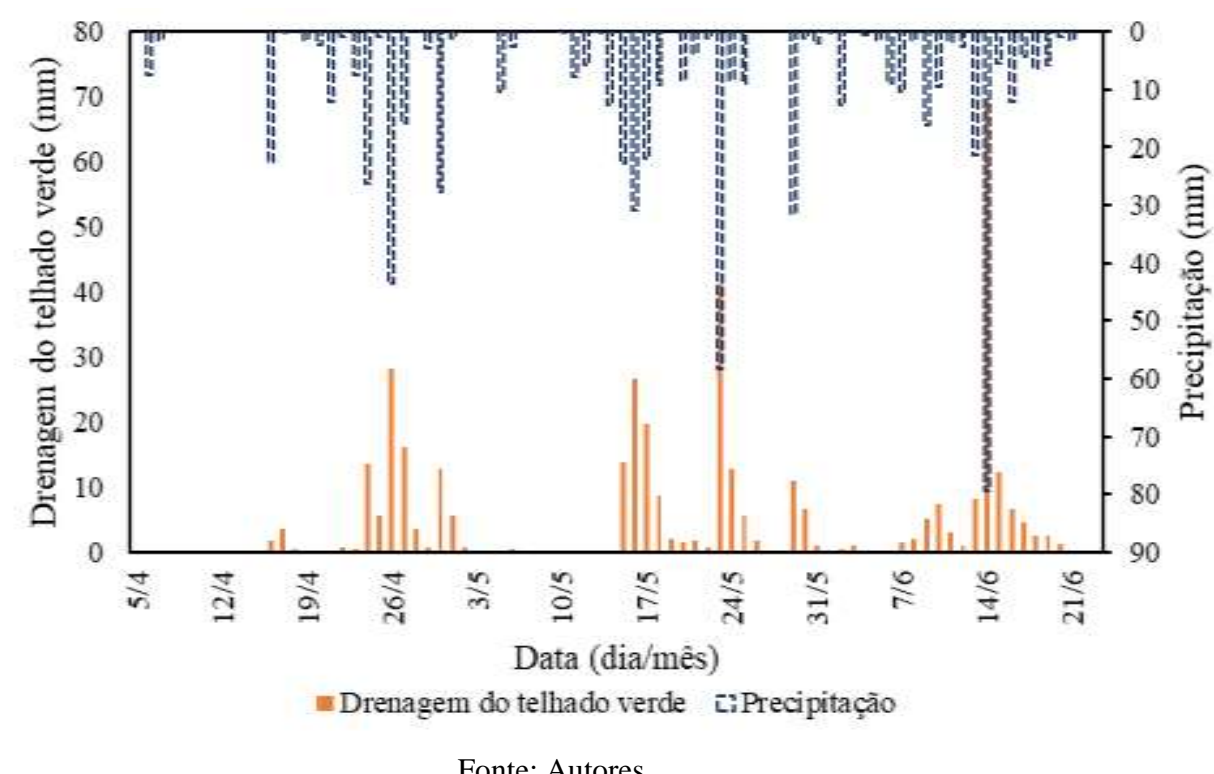

No geral, a capacidade de retenção diária do telhado verde com substrato arenoso variou entre $4,60 \%$ e $100 \%$. A retenção de 4,60\% foi observada no dia 18 de maio de 2020 para uma precipitação de 9,14 mm, após um período com eventos chuvosos diários de até $30,74 \mathrm{~mm}$. Provavelmente a capacidade de retenção foi afetada pela alta umidade do solo antecedente à precipitação. Já a retenção de 100\% foi observada durante uma precipitação de 12,7 mm (14 de maio de 2020). Essa retenção pode estar relacionada ao período de 8 dias (06 a 13 de maio de 2020) anterior, cujo foi observado apenas três eventos de precipitação, sendo chuvas muito fracas e fracas $(2,54 \mathrm{~mm}, 7,88 \mathrm{~mm}$, e $5,59 \mathrm{~mm})$.

A Figura 7 apresenta o comportamento do telhado verde, com substrato argilo arenoso, frente aos eventos de precipitação diários observados no período.

Figura 7. Precipitação e drenagem do telhado verde utilizando substrato argilo arenoso.

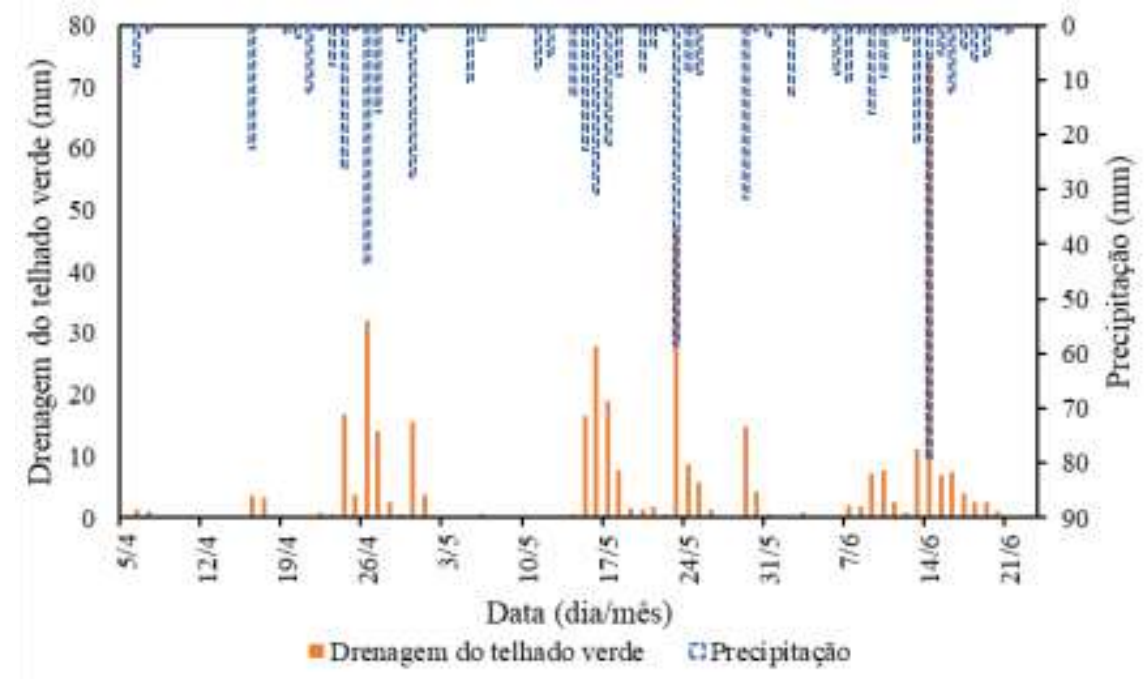

Fonte: Autores. 
O telhado verde com substrato argilo arenoso apresentou um volume drenado para o primeiro evento de chuva (7,52 $\mathrm{mm}$ ), ocorrido no dia 6 de abril de 2020. O maior volume de chuva completamente retido foi de 7,88 $\mathrm{mm}$ no dia 11 de maio de 2020, provavelmente resultante do período seco antecedente. A menor taxa de retenção foi de 1,32\% observada no dia 22 de abril de 2020 no qual ocorreu uma precipitação de $0,76 \mathrm{~mm}$. Provavelmente, esse baixo valor está correlacionado aos eventos chuvosos que ocorreram em dias anteriores.

Como observado, os telhados verdes com substrato arenoso e siltoso foram capazes de reter até $100 \%$ de precipitações fortes $(22,35 \mathrm{~mm})$ e moderadas $(12,7 \mathrm{~mm})$, respectivamente. Ainda com relação aos eventos de chuva forte, o telhado verde arenoso apresentou retenção diária, para uma precipitação de 22,35 mm, referente a 92,44\%. É importante observar que mesmo na pior configuração (substrato argilo arenso) o telhado verde apresentou uma capacidade de retenção alta para os eventos fortes $(84,61 \%)$. Essa retenção pode estar ligada ao período seco antecedente equivalente a dez dias.

Para os eventos de precipitação muito forte, observados durante o período analisado, a capacidade de retenção das águas pluviais se mostrou baixa. Esses eventos ocorreram no dia 23 de maio de 2020 (58,42 mm), onde se verificou uma retenção mínima de $19,60 \%$ e máxima de $32,78 \%$ para o substrato argilo arenoso e siltoso, respectivamente. Enquanto no dia 14 de junho de 2020 (79,25 mm), onde observou-se as maiores capacidades de retenção para o substrato composto por areia $(11,82 \%)$ e silte $(9,78 \%)$.

Porém, há uma redução na capacidade de retenção do telhado verde, influenciada pela umidade do solo antecedente aos eventos de precipitação. Essa característica também foi observada por Bouzouidja et al. (2018), no qual o desempenho dos telhados verdes variaram fortemente com o conteúdo inicial de água dos substratos. Os autores consideraram uma relação inversamente proporcional entre a capacidade de retenção e a umidade antecedente, variando de $100 \%$ de retenção para as condições mais secas a 0\% para o substrato saturado. Assim como observado por Gong et al. (2019), as condições de saturação do solo devido às precipitações anteriores, influenciam fortemente na capacidade de retenção.

Com relação às capacidades de retenção dos telhados verdes, obtidas por outros autores ao analisarem eventos de precipitação diários, foram observados valores mais baixos quando comparados a este trabalho. Como os observados por Santos et al. (2013), que mostraram uma retenção de 33,6\% e 15,5\% para precipitações de $21 \mathrm{~mm}$ e 39,5 mm, respectivamente, ao avaliarem um protótipo de telhado verde composto por areia franca em Caruaru, cidade do Agreste Pernambucano. Os autores relacionaram a baixa capacidade de retenção à profundidade do substrato $(30 \mathrm{~mm})$ utilizado na montagem do telhado verde e a condição envelhecida da vegetação.

Para Peixoto (2019), o telhado verde foi capaz de reter até 83,4\% de uma precipitação de $10 \mathrm{~mm}$ e 29,23\% para uma chuva de $66 \mathrm{~mm}$ ocorridas sob as condições climáticas da RMR, os autores não informaram a profundidade do substrato composto por terra vegetal, que se trata de uma mistura de solo natural, com restos de folhas, caules e gravetos já estabilizados. Esse material foi adquirido pelos autores em loja de jardinagem.

O retardo do escoamento gerado pelo uso do telhado verde não pode ser verificado, devido à falta de sensores de nível, no reservatório, que possibilitassem medir o início da drenagem do protótipo, impossibilitando a medida desse volume para cada um dos eventos de precipitação ocorridos durante os dias analisados. Esses valores poderiam justificar os volumes drenados pelos telhados verdes em dias em que não foram observados eventos de precipitação. Outra limitação, foi a utilização de um modelo mais simples para estimativa da evapotranspiração, optado devido ausência de dados de entrada necessários para uso do modelo padrão Penman Monteith FAO 56. Além disso, os parâmetros hidrodinâmicos dos solos não foram medidos e sim estimados por meio das funções pedotransferência. 


\section{Conclusão}

A tendência similar entre os valores simulados e os observados, além dos índices estatísticos demonstrados neste trabalho apontam uma boa representação do Hydrus-1D na predição do volume drenado pelo telhado verde após a calibração. $\mathrm{Na}$ validação, a frequência entre os valores observados e simulados verificada nos hidrogramas, assim como os resultados dos índices estatísticos comprovam a eficiência do modelo, validando, desse modo, a calibração.

As simulações do telhado verde com substratos de diferentes classes texturais mostraram uma boa capacidade de retenção diante das condições climáticas da RMR. O substrato composto por solo franco arenoso, silte, franco e franco siltoso mostraram os melhores resultados, seguidos pelos solos com classe textual areia, areia franca, franco argilo siltosa e franco argilosa, as quais não apresentaram diferença significativa entre si, com base na análise do intervalo de confiança a um nível de significância de $5 \%$.

Os telhados verdes com solos argilosos e franco argilo arenoso apresentaram as menores retenções médias. Além disso, foi observado o escoamento superficial de $0,23 \mathrm{~mm}$ e $1,89 \mathrm{~mm}$ nos solos argilo siltoso e argiloso durante o maior evento de precipitação $(79,25 \mathrm{~mm})$, que ocorreu no dia 14 de junho de 2020.

Ao observar os eventos diários, foi verificada a capacidade de retenção máxima de $100 \%$ para precipitação forte $(22,35 \mathrm{~mm})$ no telhado verde com substrato composto por silte. Para o mesmo evento de chuva o substrato arenoso e o argilo arenoso mostraram uma retenção de $91,42 \%$ e $84,61 \%$, respectivamente. Isso demonstra que, mesmo em sua pior configuração (substrato argilo arenoso), o telhado verde apresentou uma boa retenção, configurando uma boa eficiência do telhado verde frente a eventos isolados.

Além disso, foram observados eventos muito fortes de precipitação $(58,42 \mathrm{~mm})$ para a região estudada e a estrutura se mostrou capaz de reter uma parcela do volume precipitado (32,78\%) na sua melhor configuração (substrato siltoso). Para a maior precipitação do período $(79,25 \mathrm{~mm})$, o telhado verde apresentou uma baixa capacidade de retenção, com valores de 11,82 e $9,78 \%$ para o substrato arenoso e siltoso, respectivamente. Porém, isso pode estar relacionado a forte influência da umidade do substrato que antecede os eventos de precipitação na eficiência dos telhados verdes.

Para futuras pesquisas, recomenda-se realização de mais simulações utilizando diferentes composições granulométricas dentro de cada classe textural de solo. Indica-se também avaliar diferentes profundidades de substrato, com diferentes proporções entre o Solo 1 e 2. Além disso, recomenda-se a verificação do comportamento dos diferentes substratos de telhado verde sobre eventos de precipitação mais intensos, que costumam ocorrer na região do estudo. Sugere-se ainda, a realização desse estudo em regiões com diferentes condições climáticas. Essas lacunas podem ser respondidas em pesquisas futuras.

\section{Referências}

Associação Brasileira de Normas Técnicas. ABNT NBR 7181. (2016). Solo: Análise granulométrica. 13 p.

Barros, A. C., Da Silva, F. F., Araujo, P. H. V., de Medeiros, P. R. F., Neto, J. A. L. (2019). Estimativa diária da evapotranspiração de referência por Hargreaves-Samani e ajuste de parâmetros para Alagoas. IRRIGA, 24(3), 527-537.

Barros, A. H. C., Lier, Q. de J. V., Maia, A. de H. N., Scarpare, F. V. (2013). Pedotransfer Functions to Estimate Water Retention Parameters of Soils in Northeastern Brazil. Revista Brasileira de Ciências do Solo, 37, 379-391.

Bouzouidja, R., Séréd, G., Claveriee, R., Ouvrardd, S., Nuttensf, L., Lacroixc, D. (2018). Green roof aging: Quantifying the impact of substrate evolution on hydraulic performances at the lab-scale. Journal of Hydrology, 564, 416-423.

Castro, A. S., Goldenfum, J. A., Silveira, A. L. da, Dallagnol, A. L. B., Loebens, L., Demarco, C. F., Leandro, D., Nadaleti, W. C., Quadro, M. S. (2020). The analysis of green roof's runoff volumes and its water quality in an experimental study in Porto Alegre, Southern Brazil. Environ Sci Pollut Res., 1-15.

Cascone, S., Coma, J., Gagliano, Prez, A., G. (2019). The evapotranspiration process in green roofs: A review. Building and Environment, 147, $337-355$. 10.1016/j.buildenv.2018.10.024. 
CODECIR- Coordenadoria de Defesa Civil do Recife. (2007). Balanço do Alerta 2007. Boletim Técnico.

CODECIR- Coordenadoria de Defesa Civil do Recife. (2008). Balanço do Alerta 2008. Boletim Técnico.

Cosby, B. J., Hornberger, G. M., Clapp, R. B., \& Ginn, T. R. (1984). A statistical exploration of the relationship of soil moisture characteristics to the physical properties of soils. Water Resources Research. 20(6), 682-690.

Costa, I. R. DE A., Coutinho, A. P., Montenegro, S. M. G. L., Rabelo, A. E. C. de G. da C., Santos Neto, S. M. dos, Alves, E. M., Antonino, A. C. D. (2020). Sensitivity of hydrodynamic parameters in the simulation of water transfer processes in a permeable pavement. Revista Brasileira de Recursos Hídricos, 25, 1 14 .

De-Ville, S., Menon, M., \& Stovin V. Temporal variations in the potential hydrological performance of extensive green roof systems. (2018). Journal of Hydrology, 558, 564-578.

Dutra, J. B. M., \& Silva, T. F. das G. Avaliação do desempenho de telhados verdes e reservatórios de lote no amortecimento de vazões de pico em uma bacia urbana. (2020). Revista DAE, Paulo 68(227), 35-49.

Feddes, R. A., Kowalik, P. J., \& Zaradny, H. (1978). Simulation of Field Water Use and Crop Yield. John Wiley \& Sons.

Franco, B. M., Andres, C. M., Konrad, J., Tassi, R., Liberalesso T. (2019). Avaliação de escoamento pluvial em módulos de telhados verdes com diferentes substratos. Acta Brasiliensis, 3(2), 69-73.

Freitas, P. A., Oliveira, L. M. M., de Sales Barbosa, R. F., \& Montenegro, S. M. G. L. (2018). Evapotranspiração de referência diária por diferentes modelos na bacia hidrográfica do Rio Capibaribe (Pernambuco-Brasil). Revista brasileira de meio ambiente, 4(1).

Gong Y., Yin D., LI J., Zhang X., Wang W., Fang X., Shi H., \& Wang Q. (2019). Performance assessment of extensive green roof runoff flow and quality control capacity based on pilot experiments. Science of the Total Environment, 687, 505-515.

Hakimdavar, R., Culligan, P.J., Finazzi, M., Barontini, S., \& Ranzib, R. (2014). Scale dynamics of extensive green roofs: Quantifying the effect of drainage area and rainfall characteristics on observed and modeled green roof hydrologic performance. Ecol. Eng. 73, 494-508.

Hamouz, V., Lohne, J., Wood, J., \& Muthanna, T. (2018). Hydrological performance of leca-based roofs in cold climates. Water, 10(3), 263. doi: $10.3390 /$ w1 10030263 .

Hargreaves, G. H. (1994). Defining and using reference evapotranspiration, J. Irrig. Drain. Eng., 120(6), 1132-1139.

Holanda, M. A. C. R. D., \& Soares, W. D. A. (2019). Analysis of the effect of impermeability of urban soils on the infiltration of rainwater in the city of Recife, PE. Revista Ambiente \& Água, 14(4).

Holanda, M. A. C. R. de, Oliveira, D. B. C. de, Cavalcanti, A. R., Barros, C. B. R.de, \& Soares, W. de A. Uso de funções de pedotransferência na caracterização hidrodinâmica de solos pernambucanos. (2020). In anais do XV Simpósio de Recursos Hídricos do NordesteABRHidro.

Johannessen, B., Muthanna, T., Braskerud, B., Detention and retention behavior of four extensive green roofs in three nordic climate zones. (2018). Water, 10 (6), 671.

Li, S. -X., Qina, H.-P., Peng, Y.-N., \& Khuc, S. T. (2019). Modelling the combined effects of runoff reduction and increase in evapotranspiration for green roofs with a storage layer. Ecological Engineering, 127, 302-311.

Mei, C., Liu, J., Wang, H., Zhiyong, Y., Ding, X., \& Shao W. (2018). Integrated assessments of green infrastructure for flood mitigation to support robust decision-making for sponge city construction in an urbanized watershed. Science of the Total Environment, 639, 1394-1407.

Macêdo, G., \& Soares, W. (2020). Utilização de métodos de campo e laboratoriais para estimação de propriedades hidrodinâmicas do solo. Águas Subterrâneas, 34(2), 166-176.

Macêdo, K. G., Arraes, F. D. D., Lima Junior, J. C., Oliveira, W. C., \& Araujo, Y. R. (2017). Ajuste dos parâmetros do modelo de Hargreaves e samani para estimativa da evapotranspiração de referência em escala diária para Maceió-AL. Revista Brasileira de Agricultura Irrigada, 11(3), 1484-1491.

Medrado, E., \& Lima, J. E. F. W. (2014). Development of pedotransfer functions for estimating water retention curve for tropical soils of the Brazilian savanna. Geoderma Regional, 1, 59-66.

Moreira, A. B., Santos, P. F. C., Soares, D. B., \& Nóbrega, R. S. (2017). Eventos extremos e a cidade: estudo de caso dos impactos causados por um evento climático em área urbana. Revista Brasileira de Geografia Física, 10(6), 1730-1745.

Moriasi, D. N., Arnold, J. G., Van Liew, M. W., Bingner, R. L., Harmel, R. D., \& Veith, T. L. (2007). Model evaluation guidelines for systematic quantification of accuracy in watershed simulations. American Society of Agricultural and Biological Engineers, 50(3), 885-900.

Peixoto, C. de V. (2019). Análise da viabilidade técnica e econômica da aplicação de elementos reciclados em telhados verdes modulares. Dissertação (Mestrado). Universidade de Pernambuco, Recife, Pernambuco.

Pettersson, K., Maggiolo, D., Sasic, S., Johansson, P., \& Sasic-Kalagasidis, A. (2019). On the impact of porous media microstructure on rainfall infiltration of thin homogeneous green roof growth substrates, Journal of Hydrology. https://doi.org/10.1016/j.jhydrol.2019.124286

Santos, P. T. da S., Santos, S. M. dos, Montenegro, S. M. G. L., Coutinho, A. P., Moura, G. S. S. de, \& Antonino, A. C. D., (2013). Telhado verde: desempenho do sistema construtivo na redução do escoamento superficial. Ambiente Construído, 13(1), 161-174.

Shafique, M., Kim, R., \& Rafiq, M. (2018). Green roof benefits, opportunities and challenges-A review. Renewable and Sustainable Energy Reviews, 90, 757773.doi:10.1016/j.rser.2018.04.006 
Research, Society and Development, v. 10, n. 5, e57710515401, 2021

(CC BY 4.0) | ISSN 2525-3409 | DOI: http://dx.doi.org/10.33448/rsd-v10i5.15401

Silva, C. M. K., Scheffer-Basso, S. M., Carneiro, C. M., \& Guarienti, M. (2011). Desenvolvimento morfológico das gramas Esmeralda, São Carlos e Tifton 419. Ciências Agrárias, 35(3).

Silva, P. L. F. da, Oliveira, F. P. de, Martins, A. F., Pereira, W. E., Santos, T. E. D., \& Amaral, A. J. do. (2020). Caracterização físico-hídrica de solos arenosos através da curva de retenção de água, índice S e distribuição de poros por tamanho. Agrarian, Dourados, 13(50), 478-492.

Silva Junior, J. J. da, Colombo, A., Oliveira, G. C., Silva, B. M., \& Eugênio, J. E. J. (2020). Estimation of tropical soils' hydraulic properties with inverse method and tension infiltrometer field data. Rev. Ambient. Água, 15(3), e2503 - Taubaté.

Singh, J., Knapp, H. V., Arnold, J. G., \& Demissie, M. (2005). Hydrological modeling of the Iroquois river watershed using HSPF and SWAT 1. JAWRA Journal of the American Water Resources Association, 41(2), 343-360.

Soulis, K. X., Valiantzas, j. D., Ntoulas, N., Kargas, G., \& Panayiotis, A. N. (2017). Simulation of green roof runoff under different substrate depths and vegetation covers by coupling a simple conceptual and a physically based hydrological model. Journal of Environmental Management, 200, 434-445.

Sousa, N. M. (2019). Importância das praças na gestão dos recursos hídricos. Dissertação (Mestrado). Universidade de Pernambuco, Recife, Pernambuco.

Souza, W. M. de, Azevedo, P. V. de, \& Araújo, L. E. de. (2012). Classificação da Precipitação Diária e Impactos Decorrentes dos Desastres Associados às Chuvas na Cidade do Recife-PE. Revista Brasileira de Geografia Física, 2, 250-268.

Van genuchten, M. T. H. (1980). A closed-form equation for predicting the hydraulic conductivity of unsaturated soils, Soil Sci. Soc. Am. J., $44,892-898$.

Viola, F., Hellies, M., \& Deidda, R. (2017). Retention performance of green roofs in representative climates worldwide. J Hydrol, 553, 763-772.

Wang, X. O., Tian, Y. M., \& Zhao, X.H. (2017). The influence of dual-substrate-layer extensive green roofs on rainwater runoff quantity and quality. Sci. Total Environ, 592, 465-476.

Wang, H., Mei, C., Liu, J., \& Shao, W. (2018). A new strategy for integrated urban water management in China: Sponge city. Science China Technological Sciences, 61(3), 317-329.

Wanderley, L. S. de A., Nóbrega, R. S. Moreira, A. B., Anjos, R. S. dos, \& Almeida, C. A. P. de. (2018). As chuvas na cidade do Recife: uma climatologia de extremos. Revista Brasileira de Climatologia, 22, 149-164.

Xie, H., \& Liu, J. (2020). A modeling study of the interflow in the green roof. Urban Forestry \& Urban Greening, 54, 126760. 